\title{
Roadway Support in Deep “Three-Soft” Coal Seam: A Case Study in Yili Mining Area, China
}

\author{
Wenxin Li $\mathbb{D}$, ${ }^{1,2}$ Jinxiao Liu $\mathbb{D}^{1,3,2}$ Lianjun Chen $\mathbb{D}^{1},{ }^{1,4}$ Zhilu Zhong, ${ }^{2}$ and Yongle Liu $\mathbb{D}^{2}$ \\ ${ }^{1}$ Mine Disaster Prevention and Control-Ministry of State Key Laboratory Breeding Base, \\ Shandong University of Science and Technology, 579 Qianwangang Rd, Huangdao District, Qingdao 266590, China \\ ${ }^{2}$ College of Energy and Mining Engineering, Shandong University of Science and Technology, 579 Qianwangang Rd, \\ Huangdao District, Qingdao 266590, China \\ ${ }^{3}$ Key Laboratory of Deep Coal Mine Excavation Response \& Disaster Prevention and Control, \\ Anhui University of Science and Technology, Huainan 232001, China \\ ${ }^{4}$ College of Safety and Environment Engineering, Shandong University of Science and Technology, Qingdao 266590, China \\ Correspondence should be addressed to Jinxiao Liu; skd993938@sdust.edu.cn
}

Received 25 May 2020; Revised 24 July 2020; Accepted 21 December 2020; Published 18 January 2021

Academic Editor: Xue-qiu He

Copyright (c) 2021 Wenxin Li et al. This is an open access article distributed under the Creative Commons Attribution License, which permits unrestricted use, distribution, and reproduction in any medium, provided the original work is properly cited.

\begin{abstract}
This paper analyzes the large deformation of roadway in three-soft coal seam under the influence of tectonic stress. Taking the auxiliary conveying uphill roadway in Yili No. 1 Coal Mine as the engineering background, the deformation and failure mechanism of the surrounding rock and the supporting technology were studied. First, the characteristics of stress field and the surrounding rock properties of deep mining area were investigated through geostress measurement and rock mechanical test. Then, the roadway deformation and the loose circle of the supporting structure were obtained. Based on the results from measurement and theoretical analysis, we proposed a concept, i.e., "Stress adjustment-Strengthening-Grouting-Secondary support." A numerical model was established to analyze the stress distribution and the state of plasticity in the surrounding rock. According to the results of the geostress measurement and the numerical simulation, a combined support scheme was proposed, i.e., "Yielding bolt \& Shotcreting" as the primary support and "Prestressed grouting anchor cable \& U-shaped shed" as the secondary support. Finally, the underground practice showed that the proposed support scheme can effectively control the large deformation and maintain the long-term stability of the roadway in deep and three-soft coal seam. The proposed technology has guiding significance for the support design under similar mining conditions.
\end{abstract}

\section{Introduction}

The thickness of 3\# coal seam in Yili mining area is about $12.5 \mathrm{~m}$. The aquifer exists in both the roof and floor, which are mainly composed of mudstone, siltstone, and fine sandstone. The coal seam, roof, and floor are all constituted of low-strength and weather-resistant rocks, thus forming three-soft coal seam. The auxiliary conveying uphill roadway is arranged in the extra-thick coal seam. Due to the combined impact of the three-soft coal seam and the large tectonic geostress, the problem of frequent roof vibration occurred, which caused serious support difficulties such as roof crack, floor heave, etc.

Researchers have paid attention to the stability and failure mechanism of soft rock roadway. He Manchao et al. [1-3] proposed that the deformation of surrounding rock was caused by multiple factors such as weak characteristics, poor support, high geostress, groundwater, and geological structure. Li Shucai and Zhu Weishen et al. [4-10] developed physical modeling test to investigate the deformation characteristics and the mechanism of surrounding rock and obtained the impact of the excavation process. Some scholars [11-16] analyzed the influence of the joints and fissures of rock mass on the basis of considering the discontinuity of surrounding rock. Some researchers [17-22] have revised the nonlinear creep model of the surrounding rock from the perspective of long-term stability. These theoretical and practical results showed that the failure of weak rock has the main characteristics of fast rate, large deformation, and long duration. Meanwhile, the deformation characteristics and 
failure mechanism of soft-rock roadway varied under different conditions; thus, the special support measures should be applied for each condition [23, 24].

A large amount of theoretical and experimental researches have been conducted on the support technology of high-stress soft rock roadway. He et al. [25-28] proposed the support principle for the deep high-stress soft rock roadway and believed that the key of the support was to improve the resistance of the surrounding rock, release the elastic energy, and slow down the concentration process of the stress. Based on the above support principle, the support technology for the deep soft rock roadway has been investigated in the following aspects: some researchers [23, 29-31] proposed the combined support system for the deep soft rock roadway. Meanwhile, other scholars [32-35] developed new types of pressure-yielding and energy-absorbing support structure to address the high stress problem. In addition, considering the weak cementation and low-strength characteristics of soft rock, some other scientists $[36,37]$ proposed the grouting reinforcement support scheme to ensure the stability of deep three-soft coal seam roadway.

The previous studies have greatly promoted the development of the support theory and technology for the soft rock roadway. However, the surrounding rock of the threesoft coal seam has unique characteristics and complicated stress environment; thus, there is no unified standard on the control technology and supporting parameters. In addition, it is challenging for the existing support measures to maintain the stability of the soft rock roadway in a long term. Therefore, using the auxiliary conveying uphill roadway in Yili No. 1 Mine as the engineering test object, the failure mechanism and support scheme of the roadway in deep three-soft coal seam were studied.

\section{Background and Method}

2.1. Research Background. The Yili mining area is located in the southern margin of the Yili Basin. Located in the Yili microplate clamped by the Kazakhstan plate and the Tarim plate, the Yili Basin is a large inland basin between mountains formed by the north-south thrust stress of the two plates. The formation and development of the Yili Basin are controlled by the basement structure (fractures and folds). The heterogeneity of the tectonic movement determines the structural characteristics of the strong structure in north and weak structure in south, and the strong structure in east and weak structure in west. Because of the mountains formed by the Lower Paleozoic metamorphic folds and the development of the geosynclines from the Tianshan Mountains, the stress distribution in the Yili mining area is dominated by the north-south horizontal tectonic stress. In addition, the stress is always in the state of adjustment and has a concentrated trend.

Yili No. 1 Mine belongs to the Yili mining area with an average dip angle of $7^{\circ}$. The main coal seam is located in the upper part of the Xishanyao Formation, which is steady and has a uniform and layered structure. The $3 \#$ coal seam is a deep mining coal seam, and it has a ground elevation of $+1123 \mathrm{~m} \sim+1150 \mathrm{~m}$ and a buried depth of 720-1210 $\mathrm{m}$ with an average depth of $930 \mathrm{~m}$. It is an extra-thick coal seam with an average thickness of $12.35 \mathrm{~m}$ and a thickness variation coefficient of $35 \%$. The $3 \#$ coal seam is easy to be weathered and disintegrated and belongs to the soft rock class. It has the natural compressive strength of $0.50 \sim 13.1 \mathrm{MPa}$, the tensile strength of $0.1 \sim 0.5 \mathrm{MPa}$, the softening coefficient of $0.02 \sim 0.70$, and the Protodyakonov coefficient of $\mathrm{f} 2$. The lithology of the roof is dominated by mudstone, coarse sandstone, and fine sandstone, with an average thickness of $5.18 \mathrm{~m}$. The lithology of the floor is dominated by mudstone, carbonaceous mudstone, siltstone, and argillaceous siltstone, with an average thickness of $2.94 \mathrm{~m}$. The initial support is shown in Figure 1(a), and the parameters are as follows.

(1) Rock bolts: Left-handed nonlongitudinal rib screw steel metal bolts (MSGLD-400), with the dimensions of $\Phi 20 \times 2400 \mathrm{~mm}$ and spacing of $800 \times 800 \mathrm{~mm}$. The roof is arranged with 8 bolts, and the length of the anchorage section is not less than $1400 \mathrm{~mm}$. Anchor force of bolt shall not be less than $130 \mathrm{KN}$, and bolt pretightening torque shall not be less than $400 \mathrm{~N} \cdot \mathrm{m}$.

(2) Anchor cable: High strength, low relaxation, $1 * 7$ bonded steel strands, with diameter of $17.8 \mathrm{~mm}$; strength of $1860 \mathrm{n} / \mathrm{mm}$; the cross-sectional area of $191.00 \mathrm{~mm}^{2}$; elongation $\geq 3.5 \%$; and minimum breaking load of $353 \mathrm{KN}$. Arranged from the vault top to both side, the row spacing is $1960 * 2400 \mathrm{~mm}$, the anchorage force is $200 \mathrm{kN}$, and the pretension is controlled within $80-100 \mathrm{kN}$.

(3) Anchorage agent: Four K2835 anchorage agents are used for each bolt, and six K2835 anchorage agents are used for each cable.

(4) Tray: Arch high strength steel, No. Q235. The size of bolt tray is $150 * 150 * 10 \mathrm{~mm}$, and that of the anchor cable tray is $300 * 300 * 16 \mathrm{~mm}$.

(5) Reinforced welded steel fabric: $\Phi 8 \mathrm{~mm}$ reinforced grid, with a mesh size of $80 * 80 \mathrm{~mm}$.

(6) Concrete: Cement No. 425, Strength C20, ratio of cement: sand $=1: 2$; and the total thickness of shotcrete is $150 \mathrm{~mm}$. The floor hardening thickness is $300 \mathrm{~mm}$, with concrete strength of C25.

The roof and floor of the $3 \#$ coal both contain the weakly cemented soft rock with low strength and relatively welldeveloped bedding. At the same time, the existence of the aquifer in the roof and floor is not conducive to the maintenance of the roadway. Therefore, the auxiliary conveying uphill roadway is arranged in the extra-thick coal seam. After the roadway passes the $7 \#$ crossheading, the original anchor-net-cable support method could not maintain its stability. Consequently, plate cracks appeared in both sides, the net pockets occurred in the roof, and the floor undulated frequently, as shown in Figure 1(b).

2.2. Measurement of Geostress. In order to understand the geomechanical parameters and their distribution characteristics of the surrounding rock in the deep roadway of Yili No. 1 Mine, the stress relieving method was used to measure the geostress in the $7 \#$ crossheading of the $3 \#$ coal auxiliary 


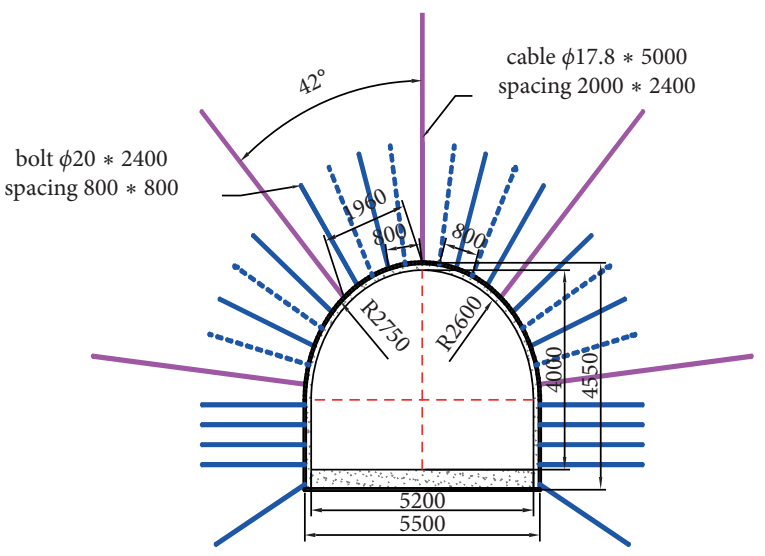

(a)

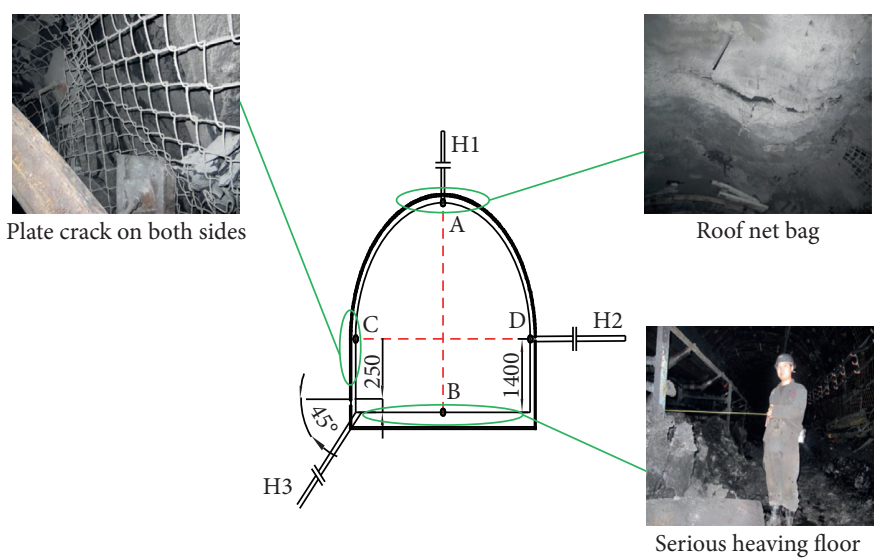

(b)

FIgURE 1: Damage features of auxiliary conveying roadway (unit: mm). (a) Initial support. (b) Monitoring arrangement.

conveying roadway. The measurement was conducted by a KX-81 hollow core inclusion triaxial geostress meter (Figure 2) developed by the Institute of Geomechanics, Chinese Academy of Geological Sciences.

The main measurement steps are described as follows: (1) drill a large hole; (2) smooth the bottom of large hole; (3) make the cone-shaped bottom of the hole; (4) make the small hole; (5) install the stress gauge; (6) record the initial data; and (7) release the geostress of the sleeve core and conduct the strain test.

\subsection{Determination of Mechanical Parameters of Surrounding} Rock. In order to obtain the mechanics parameters of the surrounding rock in the auxiliary roadway, mechanics tests were conducted on the samples obtained in the $7 \#$ crossheading and at the bottom end-point of the auxiliary roadway. The collection of samples complied with Chinese standard GB/T 23561.1-2009 "Methods for the Determination of Physical and Mechanical Properties of Coal and Rocks Part I: General Rules for Sampling”.

The processing equipment for the coal and rock samples included rock cutting machine, coring machine, radial drilling machine, stone grinding mill, and grinding machine. A total of 56 standard test pieces of coal and rock were obtained. The dimensions of the coal test pieces and rock test pieces were $\Phi 50 \times 100 \mathrm{~mm}$ and $\Phi 25 \times 50 \mathrm{~mm}$, respectively. Some standard test pieces are shown in Figure 3. The MTS815 rock servo test system (Figure 4) was applied in the tests.

2.4. Displacement and Loose Circle Observation. In order to analyze the deformation and failure characteristics, the surface displacement of roadway and the loose circle of surrounding rock were observed near the 7\# crossheading. A total of 5 surface displacement stations were set up, i.e., M1 M5 (as shown in Figure 5). The arrangement of monitoring points in each station is shown in Figure 1, in which point $A$ is on the roof, and points $C$ and $D$ are on both sidewalls. As shown in Figure 1, the floor heave in the local area exceeds $1 \mathrm{~m}$; thus, the monitoring point $B$ is not arranged. In addition, observation sections (i.e., $\mathrm{H} 1 \sim \mathrm{H} 3$ ) for the loose circle were arranged. There were three drilling holes with the dimensions of $\Phi 42 \mathrm{~mm} \times 7 \mathrm{~m}$ in each observation section, as shown in Figure 1. An intrinsically safe drilling imager was used to observe the loose circle (Figure 6)

\section{Results and Discussions}

3.1. Geostress. From the results of the geostress test (Table 1), the maximum horizontal principal stress $\sigma_{1}$ of the original rock stress field is greater than the vertical stress $\sigma_{\mathrm{v}}$. And $\sigma_{1}$ is 1.53 times as large as $\sigma_{\mathrm{v}}\left(\sigma_{\mathrm{v}} \approx \sigma_{3}\right)$, which has a great influence on the pattern of the mine pressure and the deformation and failure mode of the underground rock. The maximum horizontal principal stress $\sigma_{1}$ is 1.56 times as large as the minimum horizontal principal stress $\sigma_{2}$, which affects the tunneling direction of the roadway. Therefore, the maximum horizontal principal stress can be considered as a tectonic stress. Meanwhile, the direction of $\sigma_{1}$ is almost perpendicular to the uphill axial direction; thus, the tensile stress is generated in the surrounding rock on both sidewalls. As a result, the displacement in both sides is larger than that of the roof. Therefore, when similar roadways appear in the project, the support for the sidewalls should be strengthened.

3.2. Physical and Mechanical Properties of Three-Soft Strata. The mechanical parameters of coal and rock samples are shown in Table 2. According to the definition of ISRM (soft rock is defined as a type of rock with the uniaxial compressive strength of $0.1 \sim 25 \mathrm{MPa}$ ), it is determined that the layers where the auxiliary roadway is located belong to the three-soft seam. The lithology of the roof and floor is mainly mudstone with low strength and poor cementation. The high content of expansive minerals such as illite, kaolinite, and montmorillonite makes the rock layer easy to weather and cement. On the other hand, the coal seam has a larger thickness, higher uniaxial compressive strength than the roof and floor, and no cementation issue. Thus, the roadway is mostly located in the coal seam. 




FiguRe 2: KX-81 hollow core inclusion triaxial geostress meter.

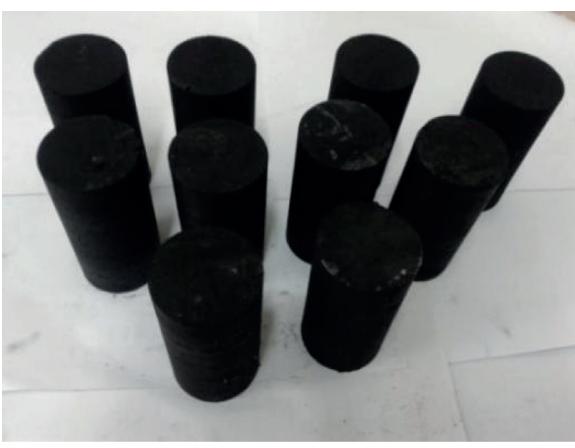

(a)

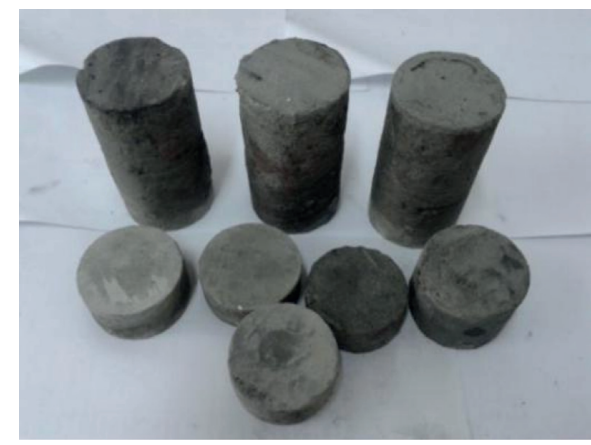

(b)

Figure 3: Some standard testing samples. (a) Coal samples. (b) Rock samples.

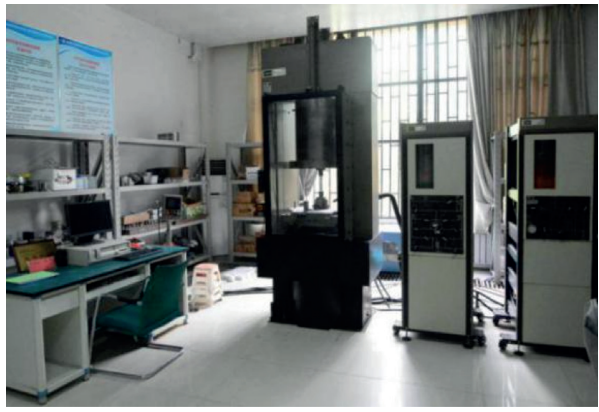

FIgURE 4: MTS rock servo test system.

3.3. Displacement of Roadway. The monitoring results on the surface displacement of the auxiliary uphill roadway are shown in Figure 7.

(1) Sidewalls: After 90 days of observation, the displacements in M1 M5 stations are stabilized at $230 \mathrm{~mm}$, $216 \mathrm{~mm}, 383 \mathrm{~mm}, 526 \mathrm{~mm}$, and $531 \mathrm{~mm}$, respectively. Taking the M5 station as an example, the variation of horizontal displacement can be divided into three stages. From 0 to 13 days, the displacement rapidly increases to $66 \%$ of the total amount of displacement, and the average changing rate is $25.0 \mathrm{~mm} / \mathrm{d}$. From 15 to 55 days, the growth rate slows down, and the changing rate is $3.1 \sim 4.0 \mathrm{~mm} / \mathrm{d}$. After 45 days, the displacement is in a stable phase, and the average rate is less than the deformation rate $(0.15 \mathrm{~mm} / \mathrm{d})$ of the horizontal support structure in the stable condition.

(2) Vault: The displacements in the monitoring stations M1 M5 tend to be flat after 90 days of observation, with the stable values of $120 \mathrm{~mm}, 83 \mathrm{~mm}, 471 \mathrm{~mm}, 419 \mathrm{~mm}$, and $474 \mathrm{~mm}$, respectively. Taking the M4 station as an example, the displacement of the roof can be divided into three stages. During 0 13 days, the displacement rapidly increases and reaches $80 \%$ of the total displacement. The average changing rate is $15.5 \mathrm{~mm} / \mathrm{d}$. From 15 to 45 days, the growth rate slows down, averaged at $0.1 \sim 2.3 \mathrm{~mm} / \mathrm{d}$. After 45 days, the displacement tends to be stable, and the average rate is less than the deformation rate $(0.10 \mathrm{~mm} / \mathrm{d})$ of the vertical support structure in the stable condition.

In summary, the displacements of the roof, floor, and both sidewalls are relatively small in the locations above 7\# crossheading in the auxiliary roadway (i.e., M1, M2). In these two locations, the deformation is in the range of $100 \sim 200 \mathrm{~mm}$, and the displacement of the two sidewalls is higher than that of the roof and floor. In addition, displacement reaches stability within 15 days. After the 7\# crossheading (i.e., M3 M5), the displacements of the roof, 


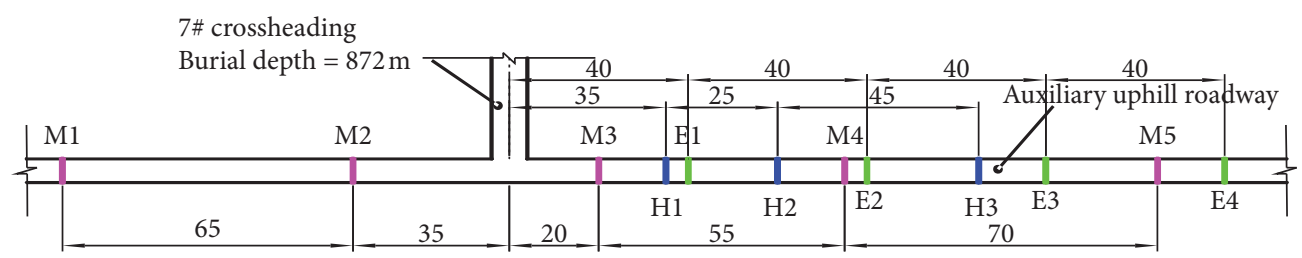

FIGURE 5: Arrangement of test stations (unit: $\mathrm{m}$ ).

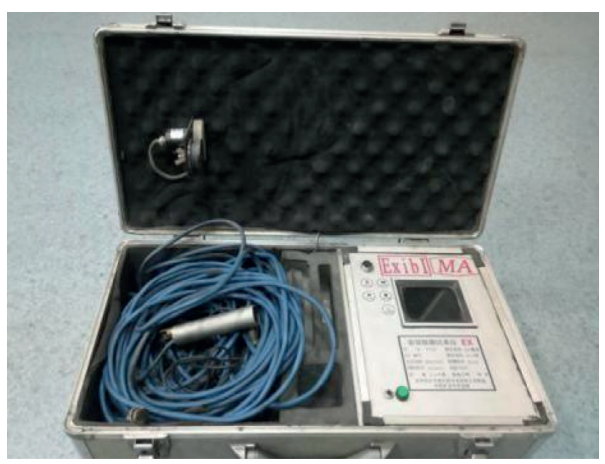

FIGURe 6: Drilling imager.

TABLE 1: Results of geostress measurement.

\begin{tabular}{lccc}
\hline Principle stress & Measurement result $(\mathrm{MPa})$ & Dip angle $\left(^{\circ}\right)$ & Dip direction $\left(^{\circ}\right)$ \\
\hline$\sigma_{1}$ & 38.83 & 3.7 & 96.69 \\
$\sigma_{2}$ & 24.85 & 7.2 & 186.2 \\
$\sigma_{3}$ & 25.33 & 81.9 & 303.22 \\
\hline
\end{tabular}

TABLE 2: Mechanical parameters of coal and rock samples.

\begin{tabular}{lcccccc}
\hline Properties & Tension $(\mathrm{Mpa})$ & Compression $(\mathrm{Mpa})$ & Young $(\mathrm{Mpa})$ & Poisson & Friction $\left(^{\circ}\right)$ & Cohesion $(\mathrm{Mpa})$ \\
\hline Fine sandstone & 0.60 & 4.22 & 1336 & 0.20 & 39 & 2.43 \\
Roof mudstone & 0.66 & 3.11 & 1032 & 0.24 & 35 & 2.19 \\
3\# coal seam & 0.21 & 6.20 & 1140 & 0.26 & 32 & 1.98 \\
Floor mudstone & 0.77 & 4.56 & 1075 & 0.23 & 36 & 42 \\
Sandy mudstone & 0.69 & 9.61 & 1991 & 0.23 & 2.32 \\
Medium sandstone & 0.72 & 5.65 & 1683 & 0.21 & 43 \\
\hline
\end{tabular}

floor, and the two sidewalls increase greatly, reaching $450 \sim 550 \mathrm{~mm}$. In addition, it takes more than 45 days for the deformation to reach stability.

3.4. Loose Circle of Surrounding Rock. The observation results on the loose circle of the surrounding rock are shown in Figure 8.

Results of H1: Cracked fractures appear at a distance of $4.45 \mathrm{~m}$ from the orifice. Circumferential and radial fractures appear at the distances of $2.9 \mathrm{~m}$ and $1.0 \mathrm{~m}$ from the orifice, respectively, and large radial fractures occur at $1.9 \mathrm{~m}$.

Results of H2: Circumferential fractures appear at a distance of $4.7 \mathrm{~m}$ from the orifice. Radial and circumferential fractures occur at the distances of $3.45 \mathrm{~m}$ and $2.44 \mathrm{~m}$, respectively. And multiple radial fractures occur at a distance of $1.6 \mathrm{~m}$ from the orifice.

Results of H3: Cracked fractures appear at a distance of $4.75 \mathrm{~m}$ from the orifice. Multiple radial cracks appear at a distance of $2.74 \mathrm{~m}$. Circumferential fractures appear at the distances of $1.72 \mathrm{~m}$ and $0.85 \mathrm{~m}$ from the orifice, respectively. In general, based on the measurement results for the auxiliary roadway, holes $\mathrm{H} 1, \mathrm{H} 2$, and $\mathrm{H} 3$ are in a relatively broken state, in which radial and circumferential fractures are relatively developed, and the integrity of the surrounding rock is poor. Below 7 \# crossheading, the damage range of the surrounding rock exceeds $4.5 \mathrm{~m}$, which is considered as a large loose circle. Since the range of the loose circle has exceeded the anchoring range of the bolt, the effectiveness of rock bolt is limited.

3.5. Control Concepts of Surrounding Rock in Deep Three-Soft Coal Seam Roadway. Through the analysis of the distribution characteristics of the mechanical parameters of the surrounding rock, as well as its deformation and failure pattern in the auxiliary conveying uphill roadway, it can be concluded that the lithologic characteristics and the 


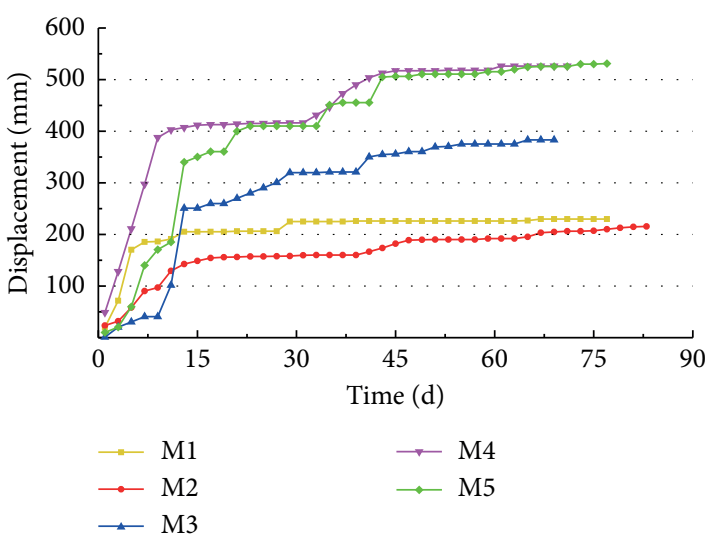

(a)

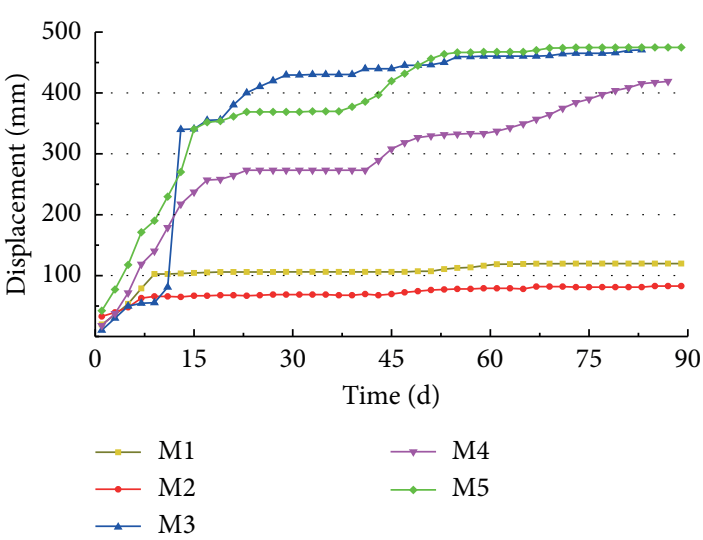

(b)

Figure 7: Monitoring results of the surface displacement of Roadway. (a) Displacement of two sidewalls. (b) Displacement of vault.



(a)

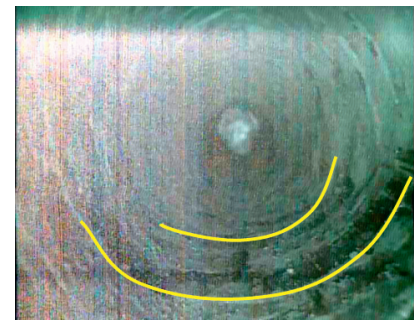

(e)

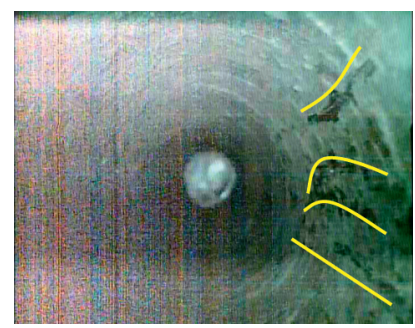

(i)

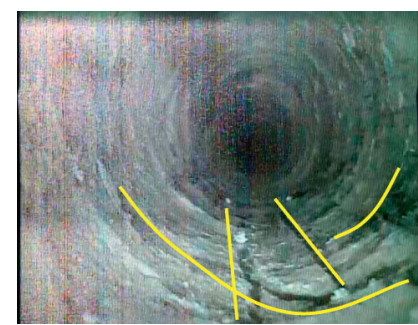

(b)



(f)

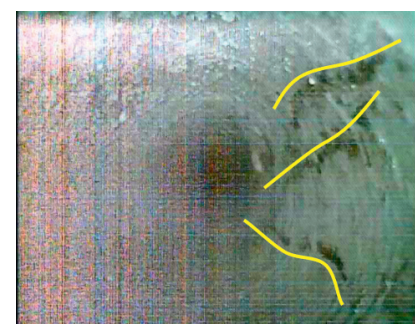

(j)

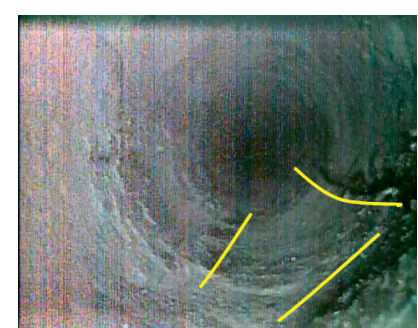

(c)

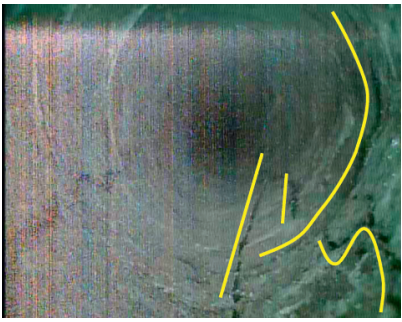

(g)

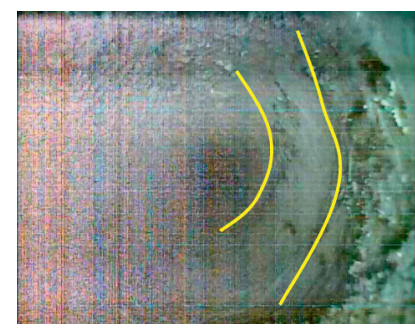

$(\mathrm{k})$

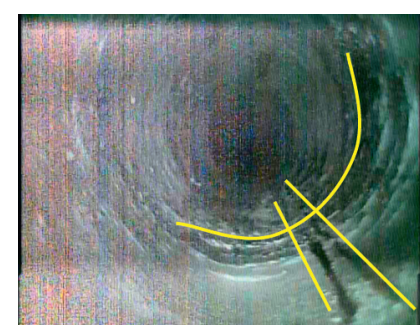

(d)

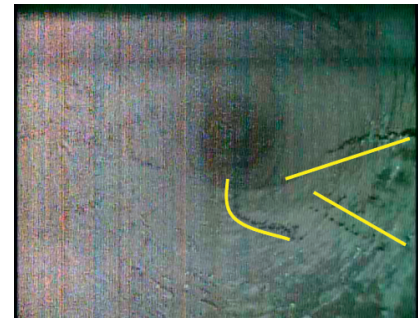

(h)

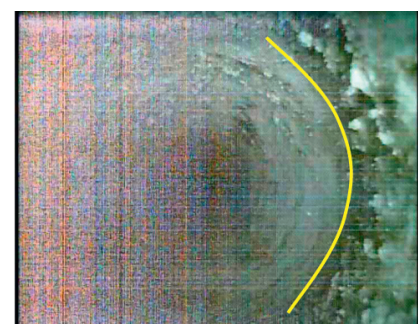

(l)

FIGURE 8: Fracture degree of the surrounding rock around drilling hole. (a) H1-4.0 m, (b) H1-2.9 m, (c) H1-1.9 m, (d) H1-1.0 m, (e) H24.7 m, (f) H2-3.45 m, (g) H2-2.44 m, (h) H3-1.6 M, (i) H3-4.75 m, (j) H3-2.74 m, (k) H3-1.72 m, (l) H3-0.85.

horizontal tectonic stress of three-soft strata are the main causes of deformation and damage of the roadway. After the excavation, the roadway has high stress concentration and a large deformation; thus, yielding support must be adopted. The radial and circumferential fractures of the surrounding rock are relatively developed and exceed the anchoring range of rock bolt, resulting in a decrease in the support effect. Therefore, anchor cable-grouting support should be applied. In summary, combined with the New Austrian Tunneling
Method, the following ideas for stability control of surrounding rock are proposed.

3.5.1. Stress Adjustment. After excavation, the normal stress on the free surface of the roadway should be adjusted to the maximum extent in the shortest time to improve the stress state of the surrounding rock. The feasible solution is described as follows: A certain surface stress is actively applied to 
the free surface of the roadway through the combination of the support by a high-strength and high-prestressing yielding bolt and the stress diffusion effect of the spraying surface layer. Meanwhile, the support by the yielding bolt ensures that the elastic deformation of the roadway is released at the beginning of the excavation, which greatly improves the antideformation ability of the bolt and reduces the impact of the stress change. Thus, the overload or destruction of the bolt in the early steps of installation can be avoided.

3.5.2. Strengthening of Surrounding Rock. After the excavation of the deep roadway, the contradiction between the high stress and low strength of surrounding rock is prominent. Therefore, it is necessary to adopt high-strength reinforcement measures to improve the inherent shear resistance of the surrounding rock and strictly limit its shear deformation along the primary and secondary fracture-slip surfaces. The reinforcement measures of the surrounding rock are mainly high-strength support, which refers to the high strength, high rigidity, and high pretension of the rock bolt and anchor cable, as shown in Figure 9.

In the combined support scheme, the yielding bolt is aimed at producing a certain amount of deformation in the surrounding rock to release part of the elasticity energy, while the high-strength anchor cable is aimed at strengthening the surrounding rock to prevent further deformation of the roadway. Due to the action of the high-strength prestressed anchor cable, a "conical" compressive stress zone (marked in green) is formed along the direction of the anchor cable in the deep surrounding rock of the roadway. When the spacing between anchor cables is small, the isolated "conical" compressive stress zones are connected to each other to form a wide range of compressive stress rings. On the other hand, the isolated tensile stress zones (marked in red) are formed at the anchoring ends of the anchor cables in an elliptical shape. Due to the small length of the bolt, the compressive stress rings (marked in brown) generated by the active support are in a small range. In the deep roadway with large sections and the soft rock (coal) roadway, the active support of the bolt is reduced to the auxiliary position, while the support of the anchor cable plays the primary role.

3.5.3. Grouting Consolidation. For the surrounding rock with poor integrity or with weak strength, grouting consolidation should be used as the main support, while the bolt support should work as a supplement. The high-strength and high-toughness grouting material is injected into the fissure of the surrounding rock to consolidate the rupture zone, thus recovering and improving its integrity and inherent shear resistance. As a result, the surrounding rock can resist the high geostress in deep areas. After the roadway is excavated, there is a process of crack expansion, so it is necessary to select the correct grouting time, as shown in the following section.

3.5.4. Secondary Support. Generally, it is impossible to completely control the deformation of deep high-stress soft rock roadway only by the support of anchor cable. In order



FIgURE 9: Combined support mechanism of bolt and anchor cable.

to expand the range of the stress-bearing ring in the surrounding rock, it is necessary to transfer the concentrated stress from the shallow area to the deep area of the surrounding rock. In another word, it is necessary to conduct a secondary strengthening support at an appropriate time. Meanwhile, the key to secondary support for the deep soft rock roadway is its timing and strength.

The above support ideas can be summarized as "stress adjustment-strengthening-grouting-secondary support." After the excavation, several types of support and reinforcement measures, i.e., the high-prestressed bolt, the highstrength grouting, and the prestressed anchor cable, were combined with the orderly temporal arrangement and the reasonable spatial interleaving to reduce the expansion range and the extent of the fracture area. For specific control projects of the surrounding rock in roadway, the geological and engineering conditions of site should be fully considered, and the above support concepts should be included as much as possible.

\section{Verification of Support Scheme}

In accordance with the stability control concept for the deep three-soft coal seam roadway, we obtained the combined support scheme of "primary yielding support + secondary grouting reinforcement" and applied it into a numerical simulation experiment. The calculation results under unsupported conditions were used as the control group. In the simulation, the displacement, stress, and plastic zone under different supporting conditions are analyzed.

\subsection{Simulation Model}

4.1.1. Establishment of Model. The FLAC3D model was established according to the geological conditions of the auxiliary conveying uphill roadway (Figure 10). The roadway was located in the middle of the coal seam with a net width of $5.2 \mathrm{~m}$, an arch height of $2.6 \mathrm{~m}$, and a wall height of $1.4 \mathrm{~m}$. The dimensions of the model were $50 \mathrm{~m} \times 40 \mathrm{~m} \times 40 \mathrm{~m}$, and the number of zones was 104400 . 


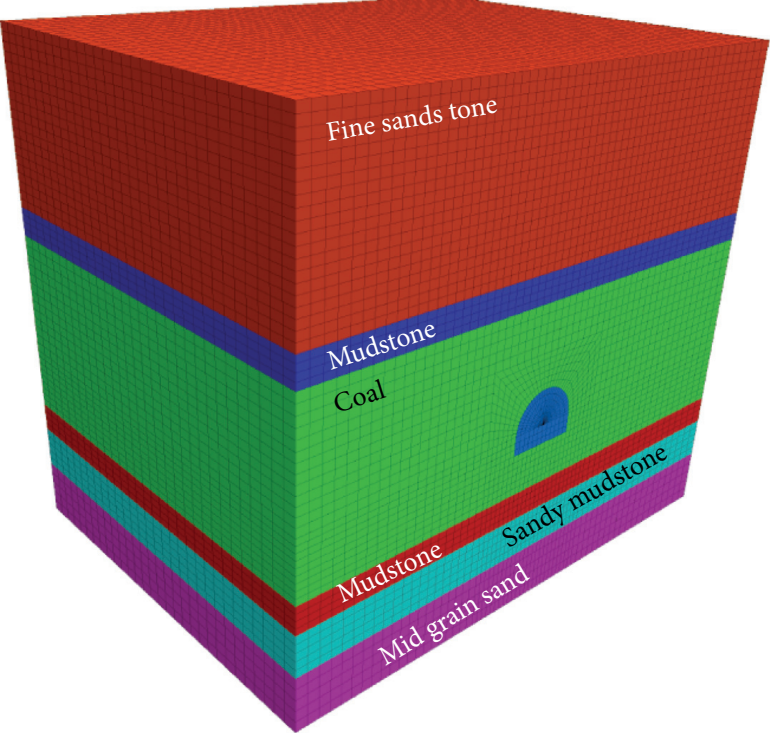

Figure 10: Simulation model.

4.1.2. Constitutive Model. The Mohr-Coulomb elasticplastic model was applied in this study. The failure criterion of the M-C model is shown in Equation (1). According to the mechanical parameters of coal and rock, the tensile strength of rock is much smaller than its compressive strength, which can be fully reflected by the $\mathrm{M}-\mathrm{C}$ criterion. Therefore, the $\mathrm{M}-\mathrm{C}$ elastic-plastic model is suitable for both plastic rock and shear failure of brittle rock.

$$
f_{s}=\sigma_{1}-\sigma_{3} \frac{1+\sin \varphi}{1-\sin \varphi}-2 c \sqrt{\frac{1+\sin \varphi}{1-\sin \varphi}}
$$

where $\sigma_{1}$ and $\sigma_{3}$ are the maximum and minimum principal stresses, respectively, and $c$ and $\varphi$ are the cohesion and internal friction angles, respectively. When $f_{\mathrm{s}}>0$, the shear failure of the material occurs. In the normal stress state, the tensile strength of the rock mass is extremely low; thus, the tensile strength criterion $\left(\sigma_{3} \geq \sigma_{\tau}\right)$ can be used to judge whether the tensile failure occurs.

4.1.3. Initial and Boundary Conditions. According to the measured results of geostress, the maximum principal stress was $\sigma_{1}=38.83 \mathrm{MPa}$, and its direction was almost perpendicular to the auxiliary roadway. The intermediate principal stress $\sigma_{2}$ and the minimum principal stress $\sigma_{3}$ were $24.85 \mathrm{MPa}$ and $25.33 \mathrm{MPa}\left(\sigma_{3} \approx \sigma_{\mathrm{v}}\right)$, respectively. Displacements were fixed for the all the east, south, west, north, and the bottom of model.

4.1.4. Structural Elements. Cable structural element was used to represent bolt and anchor cable support, and the shell structural element was used to represent shotcreting layer. The support material parameters shown in Table 3 are from the Chinese standard of "GB/T 35056-2018." In the primary support, the bolts in both the roof and floor were constructed with cable structural elements with the size of
$\Phi 20 \times 2400 \mathrm{~mm}$, the column spacing of $800 \times 800 \mathrm{~mm}$, and the pretension of $60 \mathrm{kN}$. In the secondary support, the anchor cables in both the roof and the sidewalls were constructed with cable structural elements with the size of $\Phi 22 \times 8300 \mathrm{~mm}$, the spacing of $1600 \times 1600 \mathrm{~mm}$, and the pretension of $150 \mathrm{kN}$. The anchor cables in the floor were constructed with cable structural elements with the size of $\Phi 22 \times 6500 \mathrm{~mm}$, the spacing of $2000 \times 1600 \mathrm{~mm}$, and the pretension of $150 \mathrm{kN}$. The arrangement of the structural elements in the roadway support system is shown in Figure 11.

\subsection{Numerical Simulation of Combined Support Scheme}

4.2.1. Timing of Secondary Support. Figure 12 shows the monitoring results of the displacement and velocity of the surrounding rock under the primary yielding support. When the number of iteration steps is about 3500, the surface deformation of the roadway is almost stable. The displacement of the sidewalls is about $500 \mathrm{~mm}$, and the displacement of the dome reaches $350 \mathrm{~mm}$. When the number of iteration steps is about 1000, the displacement of both sides of the roadway reaches $78 \%$ of the total amount of displacement, and the displacement of the dome reaches $87 \%$ of the total amount. According to the monitoring results of the displacement rate in the roadway, the optimal timing for the secondary support in numerical simulation is determined to be 1000 iteration steps away from the excavation.

\subsubsection{Stress of Surrounding Rock under Different Support} Conditions. Table 4 shows the stress concentration peaks of the surrounding rock under different supporting conditions. The horizontal stress concentration peak of the roadway is about $70 \mathrm{MPa}$, and its concentration factor is 1.85 . The vertical stress concentration peak is about $31 \mathrm{MPa}$, and its concentration factor is 1.26 . The maximum shear stress peak is about $27 \mathrm{MPa}$, and its concentration factor is 2.77 . Since the stress concentration of the roof and floor of the roadway is large, appropriate pressure-relief and energy-reduction measures must be used for the treatment of such roadways.

The stress is redistributed after the excavation of the roadway. Figures 13-15 show the horizontal stress, vertical stress, and maximum shear stress of the surrounding rock under different supporting conditions. In order to investigate the relationship between the distribution characteristics of stress and the strength of support, the concentration peaks were normalized for each group of stress contours.

In Figure 13, the stress concentration zone (marked in cyan and blue) is mainly distributed in the roof and floor. The area with smaller stress (in yellow and orange) is considered as the pressure-relief zone, mainly surrounding the roadway. After the secondary support, the range of the horizontal stress concentration zone and its distance to the roadway wall are reduced. Also, the range of the horizontal stress relief zone in the floor and the sidewalls is reduced.

From Figure 14, the vertical stress concentration zone (in blue) is mainly distributed on sidewalls, and the pressure- 
TABle 3: Parameters of the structural elements.

\begin{tabular}{|c|c|c|c|c|c|c|c|c|c|c|}
\hline Property & $\begin{array}{l}\text { Emod } \\
(\mathrm{GPa})\end{array}$ & $\begin{array}{l}\text { Ytension } \\
(\mathrm{kN})\end{array}$ & $\begin{array}{l}\text { Xcarea } \\
\left(\mathrm{m}^{2}\right)\end{array}$ & $\underset{\left({ }^{\circ}\right)}{G r \_f r i c}$ & $\begin{array}{l}\text { Gr_per } \\
(\mathrm{m})\end{array}$ & $\begin{array}{c}\text { Gr_coh }(\mathrm{kN} / \\
\mathrm{m})\end{array}$ & $\begin{array}{l}\text { Gr_k } \\
(\mathrm{GPa})\end{array}$ & $\begin{array}{c}\text { Density }(\mathrm{kg} / \\
\left.\mathrm{m}^{3}\right)\end{array}$ & P_ratio & $\begin{array}{l}\text { Thickness } \\
\text { (m) }\end{array}$ \\
\hline Bolt & 210 & 180 & $3.80 * 10^{-4}$ & 25 & 0.1 & 150 & 0.175 & 7850 & - & - \\
\hline Cable & 195 & 353 & $3.80 * 10^{-4}$ & 25 & 0.1 & 150 & 0.175 & 7850 & - & - \\
\hline Shell & 26 & - & - & - & - & - & - & 2400 & 0.25 & 0.15 \\
\hline
\end{tabular}

Emod is Young's modulus, Gr_coh is grout cohesive strength (force) per unit length, Gr_fric is grout friction angle (degrees), Gr_k is grout stiffness per unit length, Gr_per is grout exposed perimeter, Xcarea is cross-sectional area, and Ytension is tensile yield strength (force).

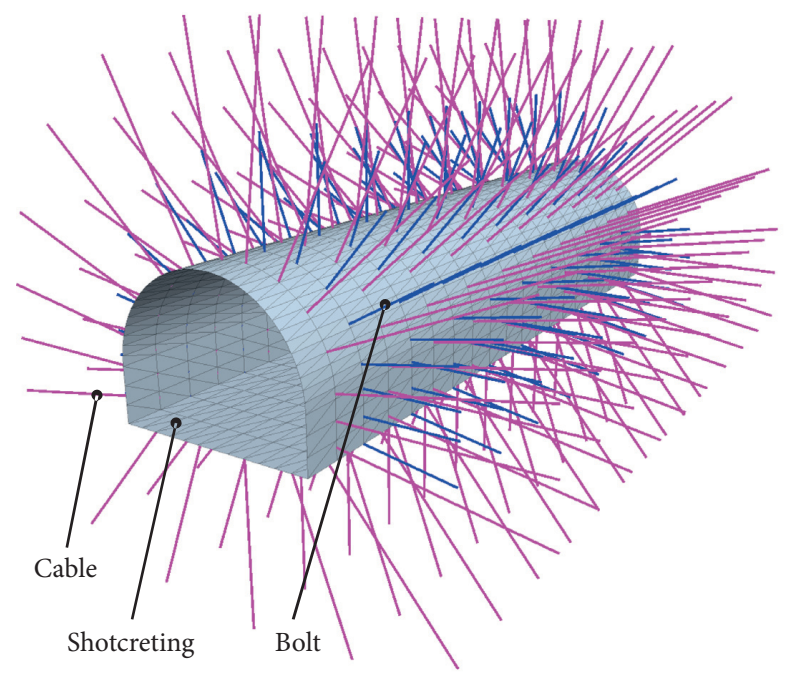

Figure 11: Structural elements.

relief zone (in orange) is mainly distributed on the roof and floor. A large range of tensile stress zone appears on the floor, indicating that the floor heave tends to occur. Therefore, the floor reinforcement measures should be taken for the treatment of this type of roadway.

In Figure 15, the concentration areas of the maximum shear stress are observed in the roof and floor, which indicates the significance of using grouting to strengthen the shear resistance of the roof and floor. Both the range of the maximum shear stress concentration zone and its distance to the surface of the roadway have the same trend as those of the horizontal stress concentration zone.

4.2.3. Plastic Zone of Surrounding Rock under Different Supporting Conditions. The plasticity areas of the surrounding rock are shown in Figure 16. The damage form is mainly shear-p. Under the unsupported condition, the plastic zone reaches $3.0 \mathrm{~m}$ in the roof, and about $3.5 \mathrm{~m}$ in the floor, including a tensile failure zone (floor heave) of about $0.5 \mathrm{~m}$. In addition, the plastic zone is about $1.3 \mathrm{~m}$ in the sidewalls. After the grouting reinforcement, the range of the tensile and shearing plastic zones of the roof is significantly reduced, indicating that the grouting reinforcement measures have a positive impact on the reinforcement.

Based on the above analysis, when the secondary grouting support was used after about 1000 iteration steps from the primary yielding support, the horizontal stress concentration and the distribution range of the plastic zone were significantly reduced. Therefore, the field application can be used to further verify the stability control concept for the surrounding rock of roadway in the three-soft coal seam and improve its combined support scheme.

\section{Field Application}

The design principle of support is clarified in "Technical specifications for rock bolting in coal mine roadways (Chinese standard, GB/T 35056-2018)." The roadway is arranged in "three-soft" environment, so the combined support of rock bolt and anchor cable is suitable for this situation. The support scheme was proposed for the auxiliary conveying uphill roadway (the sections below $7 \#$ crossheading) based on the stability control concept for the surrounding rock of roadway in the three-soft coal seam, the results of displacement monitoring, loose circle observation, and numerical simulation analysis of the roadway (Figure 17).

5.1. Support Parameters. The primary yielding support using the yielding bolt + shotcreting was applied to achieve the purposes of "stress adjustment" and "strengthening of the surrounding rock." The secondary support using prestressed grouting anchor cable $+\mathrm{U}$-shaped shed + shotcreting was applied to achieve the purposes of "strengthening of surrounding rock" and "grouting consolidation."

5.1.1. Parameters of Primary Support. Based on the analysis on the results from the geostress measurement (Table 1 in Section 3.1) and the numerical simulation (Table 4 in Section 4.2 ), the stability of the surrounding rock of auxiliary conveying roadway was highly dependent on the high horizontal stress. Since the roadway is in a high-stress environment, it is necessary for the primary support to take pressure-relief and pressure-adjustment measures. The detailed parameters are as follows:

Initial spraying: The concrete strength was C20 (L3022008LKS concrete mix ratio report), and the thickness was $50 \mathrm{~mm}$.

Bolt: In the roof and the sidewalls, each column used sixteen left-handed nonlongitudinal rib screw steel metal bolts (MSGLW-500), with the dimensions of $\Phi 20 \times 2400 \mathrm{~mm}$ and spacing of $800 \times 800 \mathrm{~mm}$. The corner bolt was tilted down by $30^{\circ}$. The length of the anchoring section was no less than $1400 \mathrm{~mm}$. The exposed length of the bolt was $30 \sim 50 \mathrm{~mm}$. 


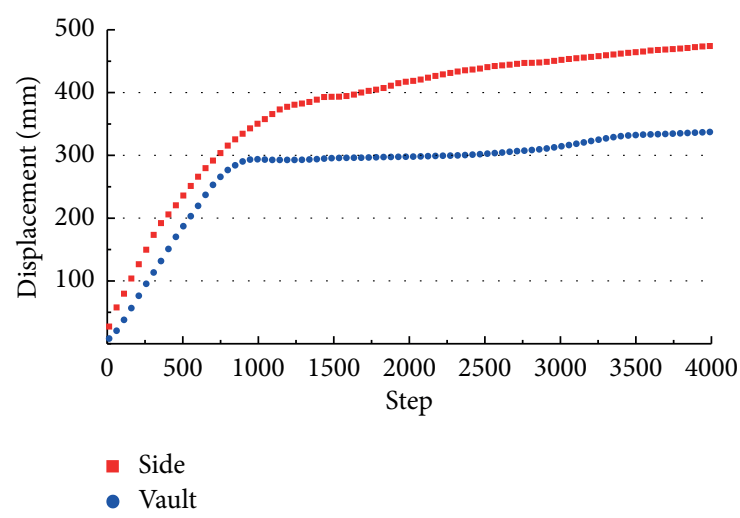

(a)

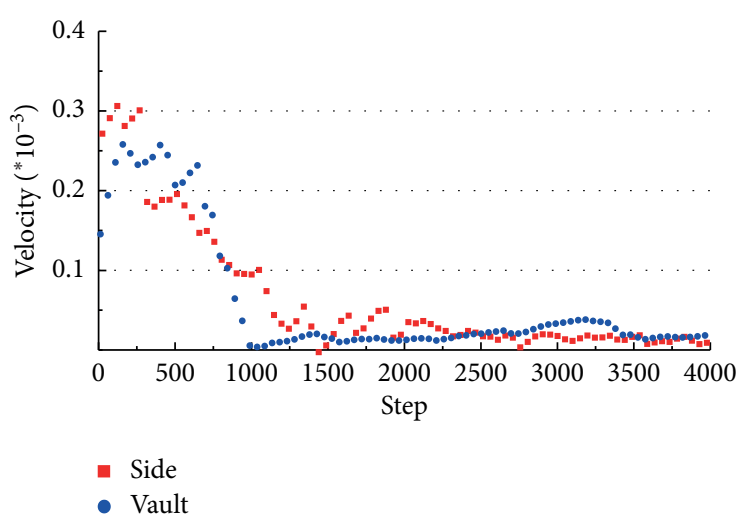

(b)

Figure 12: Displacement and velocity of surrounding rock. (a) Displacement. (b) Delocity.

TABle 4: Peak stress of surrounding rock under different supporting conditions.

\begin{tabular}{lccc}
\hline \multirow{2}{*}{ Support conditions } & \multicolumn{3}{c}{ Stress (MPa) } \\
& XX-stress & ZZ-stress & Max shear stress \\
\hline Unsupported & 71.71 & 31.41 & 24.99 \\
Primary support & 68.81 & 30.56 & 25.27 \\
Secondary support & 68.27 & 31.13 & 26.90 \\
\hline
\end{tabular}

The anchoring force of the bolt was no less than $130 \mathrm{kN}$, and the pretension was no less than $400 \mathrm{Nm}$.

Anchoring agent. Four K2335 anchoring agents were used.

Bolt tray. The bolt tray had the arched shape and high strength, steel No. Q235, and size of $150 \times 150 \times 10 \mathrm{~mm}$.

Reinforcement mesh. The reinforcement mesh was welded with $\Phi 8 \mathrm{~mm}$ steel bar with the mesh dimension of length $\times$ width $=80 \times 80 \mathrm{~mm}$. The mesh size was length $\times$ width $=2700 \times 900 \mathrm{~mm}$. Double wire network was conducted with 10\# wire. The distance between the nodes in the network was no more than $200 \mathrm{~mm}$, and the stubble length of the network was $50 \sim 100 \mathrm{~mm}$.

Second spraying. The thickness was $100 \mathrm{~mm}$, and the strength was C20.

Reinforced concrete in the floor. The reinforced concrete was made with double reinforced concrete, in which the diameter of the steel bar was $22 \mathrm{~mm}$, the cement number was $425 \#$, the concrete strength was C25, and the thickness was $300 \mathrm{~mm}$.

5.1.2. Parameters of Secondary Support. Based on the observation of the loose circle (Figure 8 in Section 3.4) and the numerical simulation (Figure 15 in Section 4.2), the surrounding rock in the roof and floor was subject to large shear stress. Therefore, in the secondary support, the surrounding rock in the roof and floor should be strengthened. Meanwhile, the existence of fissures provided ideal conditions for grouting the surrounding rock. The results of roadway displacement monitoring (Figure 7 in Section 3.3) and velocity monitoring (Figure 12 in Section 4.2) showed that, after the primary yielding support, the displacement rate of the roadway was gradually reduced. When the primary yielding support was applied for 13 to 15 days, the displacement was expected to reach about $80 \%$ of the total amount, and the displacement rate was expected to reduce to a small range. Therefore, the best time to apply the secondary support is 13 to 15 days after the application of the primary support. The detailed parameters of the secondary support are as follows:

Anchor cable. Eight high-strength prestressed steel strands with the dimensions of $\Phi 22 \times 8300 \mathrm{~mm}$ were used in each row. They were arranged from the roof to both sidewalls with a spacing of $1600 \mathrm{~mm}$ and a pretension of $200 \mathrm{kN}$. Two highstrength prestressed steel strands with the dimensions of $\Phi 22 \times 6500 \mathrm{~mm}$ were used in the floor with a spacing of $2000 \times 1600 \mathrm{~mm}$. The anchor cable was inclined downward by $30^{\circ}$. The grouting anchor cable was alternately arranged with the anchor cable, as shown in Figures 17(c)-17(d)).

Grouting anchor cable. Seven $1 \times 19$ strand steel strand prestressed grouting anchor cables with the dimensions of $\Phi 22 \times 8300 \mathrm{~mm}$ were used for each row in the roof and two sidewalls. The grouting anchor cables were arranged from the center line of the roof to both sidewalls with the spacing of $1600 \mathrm{~mm}$. Three prestressed grouting anchor cables with the dimensions of $\Phi 22 \times 6500 \mathrm{~mm}$ were used in the floor, which were arranged from the center line of the floor to the sides with the distance of $2000 \mathrm{~mm}$ and a row spacing of $1600 \mathrm{~mm}$. The anchoring force was $400 \mathrm{kN}$, and the pretension was $250 \sim 300 \mathrm{kN}$.

Anchor cable tray. The high-strength adjustable heart supporting tray and locks with the dimensions of $300 \times 300 \times 16 \mathrm{~mm}$ were used. Their bearing capacity was no 


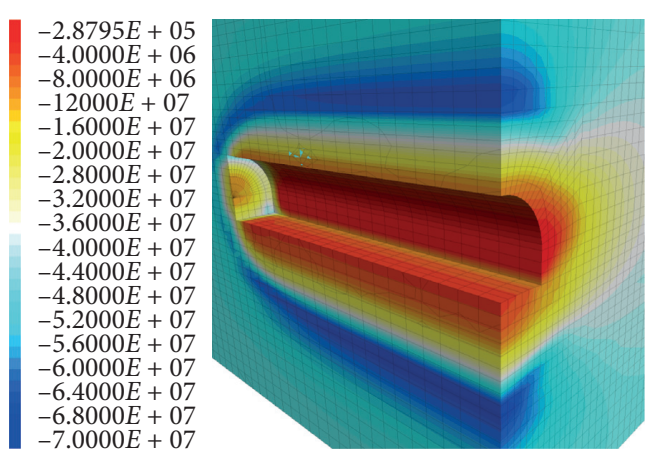

(a)

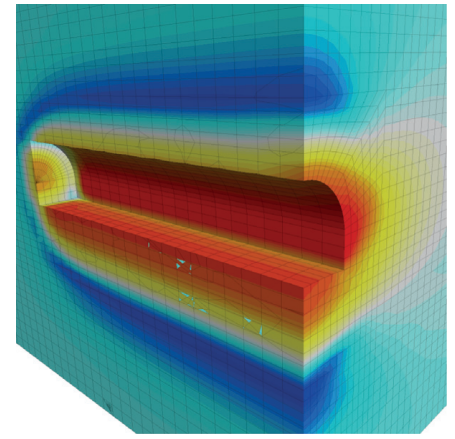

(b)

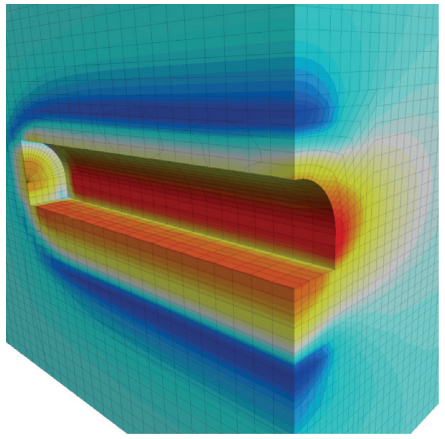

(c)

Figure 13: XX-stress. (a) Unsupported. (b) Primary support. (c) Secondary support.

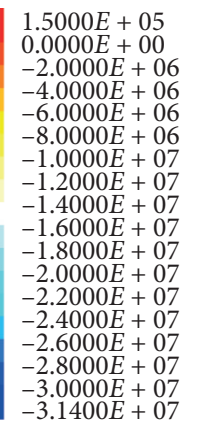

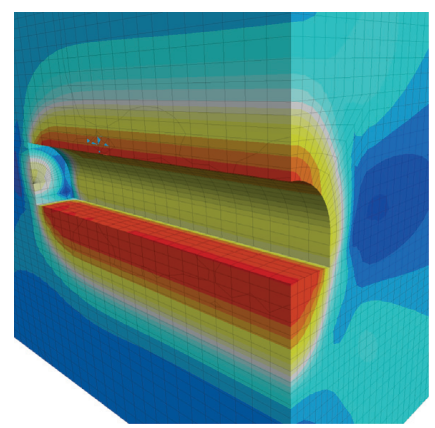

(a)

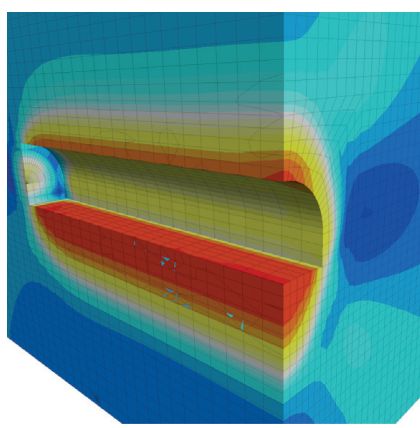

(b)

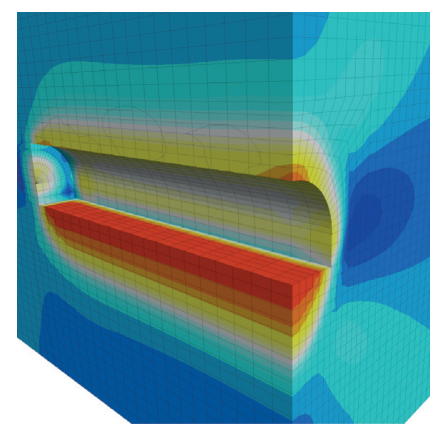

(c)

Figure 14: ZZ-stress. (a) Unsupported. (b) Primary support. (c) Secondary support.

$2.7000 E+07$

$2.5000 E+07$

$2.2500 E+07$

$2.0000 E+07$

$1.7500 E+07$

$1.5000 E+07$

$1.2500 E+07$

$1.0000 E+07$

$7.5000 E+06$

$5.0000 E+06$

$2.5000 E+06$

$8.3376 E+05$

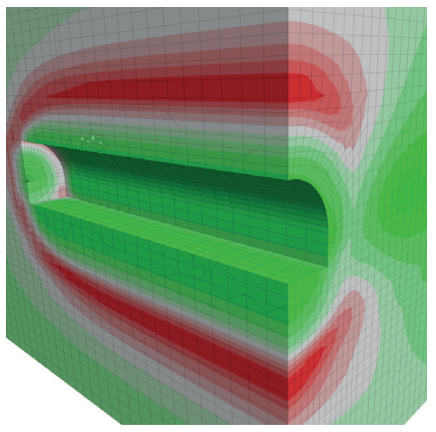

(a)

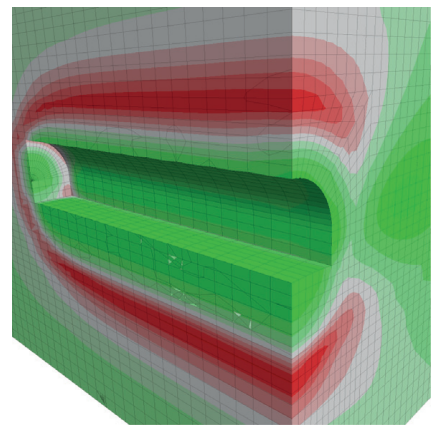

(b)

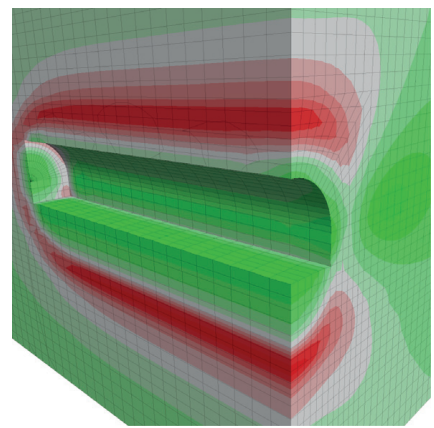

(c)

Figure 15: Max shear stress. (a) Unsupported. (b) Primary support. (c) Secondary support.

shear-n shear-p

shear-n shear-p tension-p

shear-p

shear-p tension-p

tension-p



(a)

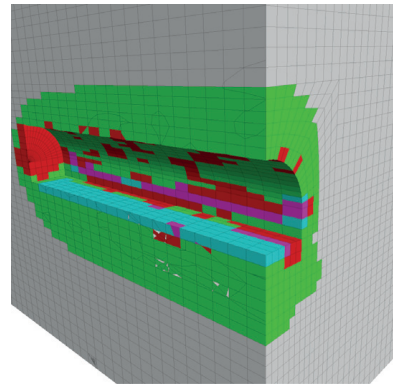

(b)

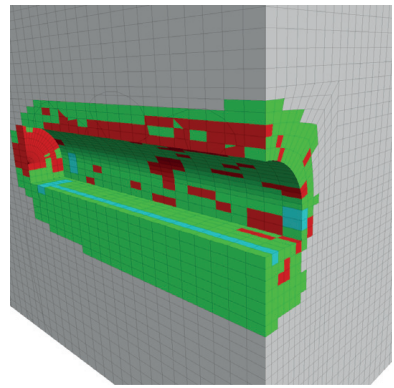

(c)

Figure 16: State of plastic zone. (a) Unsupported. (b) Primary support. (c) Secondary support. 


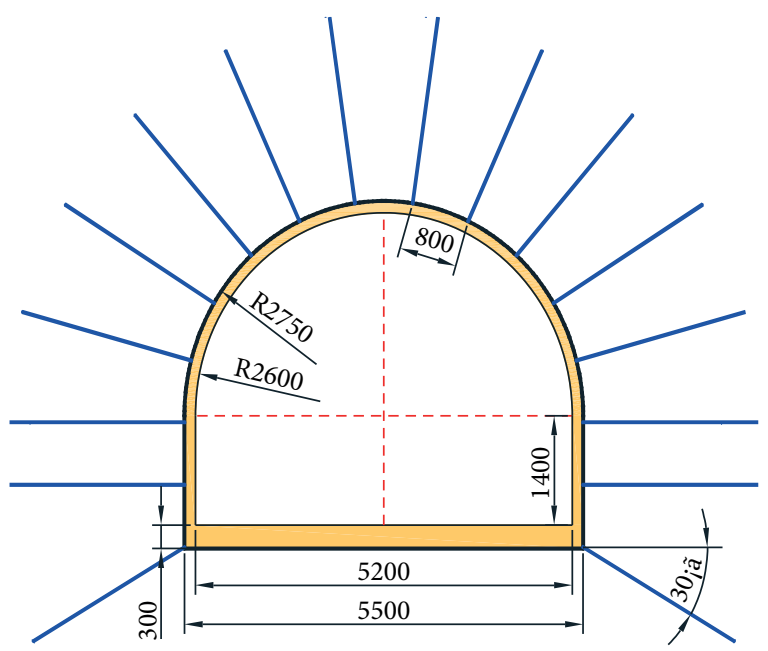

(a)

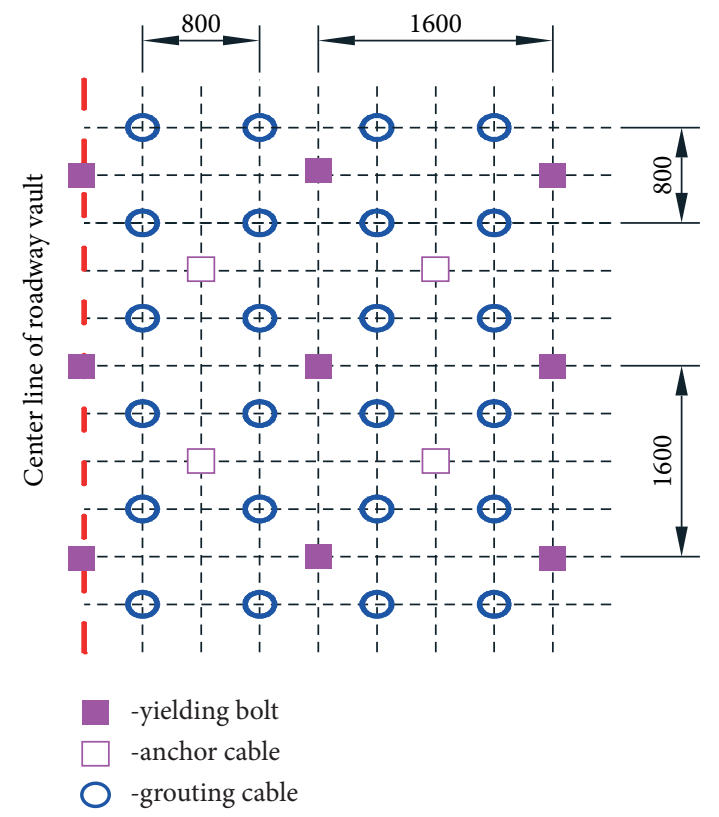

(c)

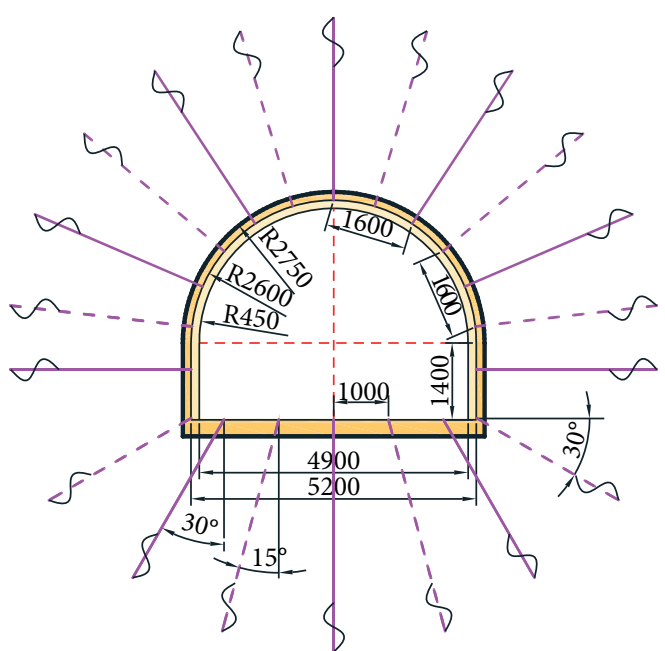

(b)

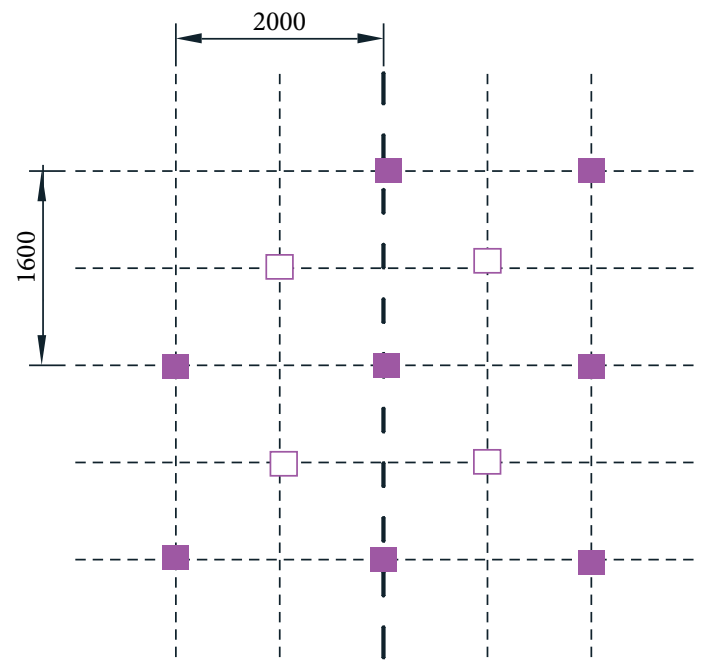

(d)

FIgURE 17: Combined support scheme (Unit: mm). (a) Primary support. (b) Secondary support. (c) Reinforcement of dome and sidewalls. (d) Reinforcement of floor.

less than $40 t$. There were grouting holes with the diameter of $20 \mathrm{~mm}$ on the tray.

Anchoring method. The full-length prestressed anchoring was used. First, a K2335 and two Z2360 low-viscosity resin rolls were used to anchor the end. After the anchor cable was stretched, the cement slurry was injected into the free section of the anchor cable through the reserved grouting pipe, and the grouting pressure was $1.5 \mathrm{MPa}$.

Grouting material. The cement slurry (525\# ordinary Portland cement with XPM nanogrouting additive) was used. The water-cement ratio of the cement slurry was adjusted within a small range according to the on-site grouting effect. The water-cement ratio was generally in the range of $0.5: 1$ to $0.7: 1$. The amount of XPM additive should be $8 \% \sim 10 \%$ of the weight of cement.

U-shaped shed. The 25\# U-shaped steel was used, which consisted of 5 sections. Two pairs of cables were used at each joint between adjacent sections. The tightening torque of the cable nut was not less than $300 \mathrm{~N} \cdot \mathrm{m}$. The upper cable of the lap joint was fixed to the shed and connected two sheds. The joint of the sheds was in a line along the roadway. The length of each bracket lap of the U-shaped shed was $500 \mathrm{~mm}$, and the lap joint was fixed by two cables. The spacing between cables was no less than $200 \mathrm{~mm}$, and the row spacing was $800 \mathrm{~mm}$.

Reinforcement mesh. The steel mesh was laid after the shed was built. The mesh was connected to the roof and sidewalls 


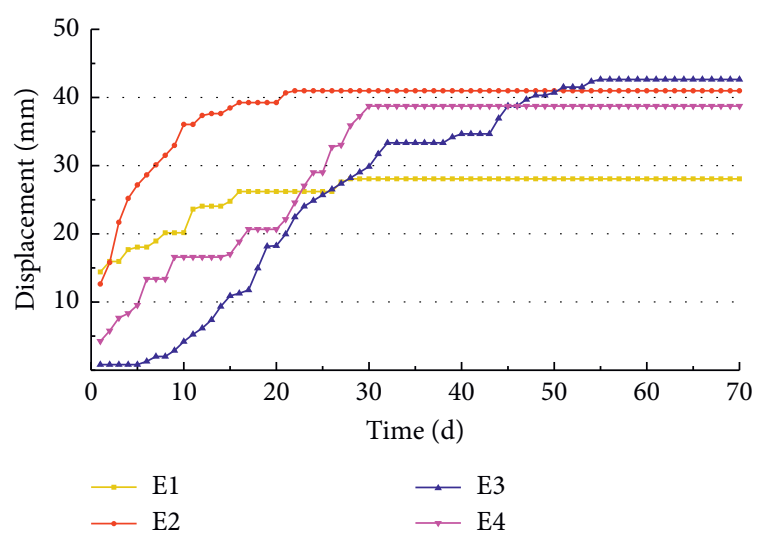

(a)

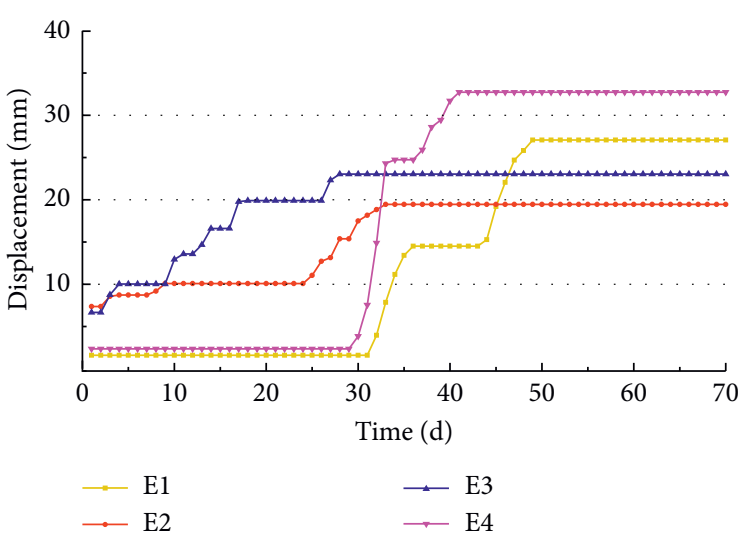

(b)

FIGURE 18: Monitoring results of displacement under combined support. (a) Displacement of both sidewalls. (b) Displacement of roof.

using the cement backboard. The backboard should not be loose or having gap with the roof or sidewall. .

Grouting. Grouting was applied for consolidation after the shed was built. The thickness of the grouting was $150 \mathrm{~mm}$, and the strength was C40 (using P.O42.5 cement, plus 10\% cement additive).

5.2. Evaluation of Support Effect. After the completion of the combined support, the stations E1 E4 were set below the 7\# crossheading to monitor the displacement of roof and sidewalls. The results are shown in Figure 18.

(1) With combined support, the deformation of the roadway tended to be steady after two months. The maximum relative displacement of the two sidewalls was $42 \mathrm{~mm}$, and the maximum displacement of the roof was $33 \mathrm{~mm}$.

(2) The deformation of the roadway was small, but it took a long time, i.e., 30 50 days, for the deformation to be stable.

(3) The displacement of the two sidewalls was greater than that of the dome. The main reason was that the horizontal stress was large, which can easily cause tensile failure of the surrounding rock of the sidewalls.

After observation for more than two months, the roof subsidence rate of all the stations is less than that of the initial supporting condition, which can be regarded as the deformation rate of vertical support structure in a stable state (no more than $0.1 \mathrm{~mm} / \mathrm{d}$ ). When the approaching rate of two sidewalls is less than $0.15 \mathrm{~mm} / \mathrm{d}$, the horizontal deformation of supporting structure approaches a stable state. The monitoring results showed that, compared with the deformation amount of roadway under the initial support condition, the displacement amount of surrounding rock of roadway after repair and reinforcement is significantly reduced. The combined support scheme of "yielding bolt + shotcreting" for primary support and "prestressed grouting anchor cable + U-shaped shed" for secondary support had a significant effect in limiting the large deformation. Using the proposed support scheme, the stability of the three soft strata roadway can meet the production demand.

\section{Conclusions}

(1) The auxiliary conveying uphill roadway is a typical three-soft coal seam roadway. The surrounding rock has poor cementation and low strength. Due to the influence of the deep horizontal structural stress, roof vibration occurs, causing floor heave and roof net pockets. The large tensile stress generated by the horizontal tectonic stress causes the sidewalls of roadway to break. Under the combined action of three-soft characteristics and horizontal tectonic stress, the initial deformation rate is large, its duration is long, and the surrounding rock is easily to loose and break. The radial and circumferential fractures of the surrounding rock are relatively developed and exceed the anchoring range of the bolt, causing the support effect by bolt to decrease. However, the existence of the cracks also provides ideal conditions for the grouting in surrounding rock.

(2) In the early stage of support, the stress concentration is high, and the deformation of the surrounding rock is large. Thus, the primary yielding support is used. The yielding space is reserved to release the stress of surrounding rock and allow the roadway to deform. As a result, the degree of stress concentration is moderately reduced. In the secondary support, the fissure of the surrounding rock is filled by grouting, and the integrity and mechanical properties of the surrounding rock are improved. As a result, a large range of surrounding rock in roof and floor is strengthened.

(3) When the secondary grouting support is conducted after 1000 iteration steps of the primary yielding support, there is a good effect on the stress adjustment and plastic zone control of the roof and floor. 
Based on the displacement results from both field measurement and numerical simulation, after the primary yielding support, the changing rate of the displacement of the roadway is gradually reduced. When the primary yielding support is applied for $13 \sim 15$ days, the displacement is expected to reach about $80 \%$ of the total amount of displacement, and that is the best time to apply the secondary support.

(4) To improve the stability of the roadway in three-soft coal seam under the influence of deep high-level tectonic stress, the control concept of "stress adjustmentstrengthening-grouting-secondary support" was proposed. In addition, the corresponding combined support scheme of "yielding bolt + shotcreting" for primary support and "prestressed grouting anchor cable +U-shaped shed" for secondary support was developed. Through on-site verification, the combined support scheme can improve the stress conditions of the surrounding rock and integrate the support domain and the surrounding rock to form a whole load-bearing structure. The research results provide theoretical reference and field experience for the support of roadway in the deep three-soft coal seam.

\section{Data Availability}

All data used to support the findings of this study are available from the corresponding author upon request.

\section{Additional Points}

Highlights. (i) A combined support scheme for the roadway in deep three-soft strata was proposed, i.e., "Yielding bolt + shotcreting" for primary support, and "prestressed grouting anchor cable + U-shaped shed" for secondary support. The support scheme provides technical guidance for the design of support in the deep, high-stress, and softrock roadway. (ii) The results showed that the soft characteristics of the surrounding rock and the high horizontal tectonic stress were the main factors that caused the deformation and destruction of the auxiliary conveying roadway. (iii) Through field monitoring and FLAC3D numerical simulation, the optimal time for the secondary support was 13-15 days after the primary support, when the displacement reached about $80 \%$ of its estimated total amount.

\section{Conflicts of Interest}

The authors declare that they have no known competing financial interests or personal relationships that can influence the work reported in this paper.

\section{Acknowledgments}

This work was supported by the Key Laboratory of Deep Coal Mine Excavation Response and Disaster Prevention and Control, Anhui Province (Anhui University of Science and Technology), Huainan, China, 232001 (KLDCMERDPC16101 and 01CK05002), Jinxiao Liu (liujinxiao1999@126.com), and the Key Development Plan Financial Aid Project of Shandong, China (2018GSF116002), Xinguo Zhang (Zhangxg@sdust.edu.cn).

\section{References}

[1] M. C. He, G. F. Li, J. Wang, and J. Cai, "Study on supporting design for large area serious roof caving of deep soft rock roadway in Xing'an coal mine," Chinese Journal of Rock Mechanics and Engineering, vol. 26, no. 5, pp. 959-964, 2007.

[2] S. Chen, A. Wu, Y. Wang, X. Chen, R. Yan, and H. Ma, "Study on repair control technology of soft surrounding rock roadway and its application," Engineering Failure Analysis, vol. 92, pp. 443-455, 2018.

[3] Q. Wang, R. Pan, B. Jiang et al., "Study on failure mechanism of roadway with soft rock in deep coal mine and confined concrete support system," Engineering Failure Analysis, vol. 81, pp. 155-177, 2017.

[4] Y.-Z. Lee and W. Schubert, "Determination of the round length for tunnel excavation in weak rock," Tunnelling and Underground Space Technology, vol. 23, no. 3, pp. 221-231, 2008.

[5] V. Marinos, "Tunnel behaviour and support associated with the weak rock masses of flysch," Journal of Rock Mechanics and Geotechnical Engineering, vol. 6, no. 3, pp. 227-239, 2014.

[6] X. Sun, F. Chen, C. Miao et al., "Physical modeling of deformation failure mechanism of surrounding rocks for the deep-buried tunnel in soft rock strata during the excavation," Tunnelling and Underground Space Technology, vol. 74, pp. 247-261, 2018.

[7] W. S. Zhu, Y. Li, S. C. Li et al., "Quasi-three-dimensional physical model tests on a cavern complex under high in-situ stresses," International Journal of Rock Mechanics and Mining Sciences, vol. 48, no. 2, pp. 199-209, 2011.

[8] S. C. Li, Q. Wang, H. T. Wang et al., "Model test study on surrounding rock deformation and failure mechanisms of deep roadways with thick top coal," Tunnelling and Underground Space Technology, vol. 47, pp. 52-63, 2015.

[9] Z. X. Zhang, Y. Xu, P. H. S. W. Kulatilake, and X. Huang, "Physical model test and numerical analysis on the behavior of stratified rock masses during underground excavation," International Journal of Rock Mechanics and Mining Sciences, vol. 49, pp. 134-147, 2012.

[10] Q. B. Zhang, L. He, and W. S. Zhu, "Displacement measurement techniques and numerical verification in $3 \mathrm{D}$ geomechanical model tests of an underground cavern group," Tunnelling and Underground Space Technology, vol. 56, pp. 54-64, 2016.

[11] X. X. Yang, P. H. S. W. Kulatilake, H. W. Jing, and S. Q. Yang, "Numerical simulation of a jointed rock block mechanical behavior adjacent to an underground excavation and comparison with physical model test results," Tunnelling and Underground Space Technology, vol. 53, pp. 109-119, 2015.

[12] S. Shreedharan and P. H. S. W. Kulatilake, "Discontinuumequivalent continuum analysis of the stability of tunnels in a deep coal mine using the distinct element method," Rock Mechanics and Rock Engineering, vol. 49, no. 5, pp. 1903-1922, 2016.

[13] X. Chen, H. Guo, P. Zhao et al., "Numerical modeling of large deformation and nonlinear frictional contact of excavation boundary of deep soft rock tunnel," Journal of Rock Mechanics and Geotechnical Engineering, vol. 3, pp. 421-428, 2011. 
[14] A. H. Stephen, D. S. Fiorenza, and V. Gioacchino, "Monitoring fracture propagation in a soft rock (neapolitan tuff) using acoustic emissions and digital images," Pure Appl. Geophys.vol. 163, pp. 2171-2204, 2006.

[15] P. Cao, Y. L. Wen, Y. Wang et al., "Study on nonlinear damage creep constitutive model for high-stress soft rock," Environmental Earth Sciences, vol. 75, p. 900, 2016.

[16] B. Mishra and P. Verma, "Uniaxial and triaxial single and multistage creep tests on coal-measure shale rocks," International Journal of Coal Geology, vol. 137, pp. 55-65, 2015.

[17] F. Wu, J. F. Liu, and J. Wang, "An improved Maxwell creep model for rock based on variable-order fractional derivatives," Environmental Earth Sciences, vol. 73, no. 11, pp. 6965-6971, 2015.

[18] H. Z. Liu, H. Q. Xie, J. D. He, M. L. Xiao, and L. Zhuo, "Nonlinear creep damage constitutive model for soft rocks," Mechanics of Time-dependent Materials, vol. 21, no. 1, pp. 73-96, 2017.

[19] M. S. A. Siddiquee, M. S. Islam, and F. Tatsuoka, "Development of a nonlinear model for soft rock and its applications," Geotechnical and Geological Engineering, vol. 31, no. 2, pp. 627-645, 2013.

[20] H. Zhu, B. Ye, Y. Cai, and F. Zhang, “An elasto-viscoplastic model for soft rock around tunnels considering overconsolidation and structure effects," Computers and Geotechnics, vol. 50, pp. 6-16, 2013.

[21] Y. Yang, C. K. Zhu, and D. Y. Chong, "Catastrophe mechanism and disaster countermeasure for soft rock roadway surrounding rock in Meihe mine," International Journal of Mining Science and Technology, vol. 25, no. 3, pp. 407-413, 2016.

[22] J. B. Bai, X. Y. Wang, and M. K. Jia, "Theory and application of supporting in deep soft roadways," Chinese Journal of Geotechnical Engineering, vol. 30, no. 5, pp. 632-635, 2008.

[23] Li Chong, Z. Wang, and T. Liu, "Principle and practice of coupling support of double yielding shell of soft rock roadway under high stress," International Journal of Mining Science and Technology, vol. 24, pp. 513-518, 2014.

[24] G. C. Zhang, Z. J. Wen, S. J. Liang et al., "Ground Response of a gob-side entry in a longwall panel extracting 17 m-thick coal seam: a case study," Rock Mechanics and Rock Engineering, vol. 53, no. 2, pp. 497-516, 2019.

[25] M. He, W. Gong, J. Wang et al., "Development of a novel energy-absorbing bolt with extraordinarily large elongation and constant resistance," International Journal of Rock Mechanics and Mining Sciences, vol. 67, pp. 29-42, 2014.

[26] M. He, "Latest progress of soft rock mechanics and engineering in China," Journal of Rock Mechanics and Geotechnical Engineering, vol. 6, no. 3, pp. 165-179, 2014.

[27] G. Li, Z. Jiang, C. Lv, C. Huang, G. Chen, and M. Li, "Instability mechanism and control technology of soft rock roadway affected by mining and high confined water," International Journal of Mining Science and Technology, vol. 25, no. 4, pp. 573-580, 2015.

[28] W. J. Yu, W. J. Wang, and W. Z. Huang, "Deformation mechanism and rework control technology of high stress and soft rock roadway," Journal of China Coal Society, vol. 39, no. 4, pp. 614-623, 2014.

[29] L. Jiang, P. Kong, J. Shu et al., "Numerical Analysis of Support Designs Based on a Case Study of a Longwall Entry," Rock Mechanics and Rock Engineering, vol. 52, no. 9, pp. 33733384, 2019.

[30] X. S. Liu, J. G. Ning, Y. L. Tan et al., "Coordinated supporting method of gob-side entry retaining in coal mines and a case study with hard roof," Geomechanics and Engineering, vol. 15, no. 6, pp. 1173-1182, 2018.

[31] D. Fan, X. Liu, Y. Tan et al., "An innovative approach for gobside entry retaining in deep coal mines: a case study," Energy Science \& Engineering, vol. 7, pp. 2321-2335, 2019.

[32] Y. Kang, Q. Liu, G. Gong, and H. Wang, "Application of a combined support system to the weak floor reinforcement in deep underground coal mine," International Journal of Rock Mechanics and Mining Sciences, vol. 71, pp. 143-150, 2014.

[33] A. Anders, "Laboratory Testing of a new type of energy absorbing rock bolt," Tunneling and Underground Space Technology, vol. 20, no. 4, pp. 291-330, 2005.

[34] L. Sun, H. Wu, B. Yang, and Q. Li, "Support failure of a highstress soft-rock roadway in deep coal mine and the equalized yielding support technology: a case study," International Journal of Coal Science \& Technology, vol. 2, no. 4, pp. 279286, 2015.

[35] S. G. Jing, Q. Z. Wang, and J. Chen, "Study on strengthening control mechanism with support and cable for roadway in "three-soft" coal seam during deep mining," Journal of mining and safety engineerin, vol. 31, pp. 938-944, 2014.

[36] Z.-B. Guo, P.-Y. Guo, M.-H. Huang, and Y.-G. Liu, "Stability control of gate groups in deep wells," Mining Science and Technology (China), vol. 19, no. 2, pp. 155-160, 2009.

[37] Y. L. Lu, L. G. Wang, B. Zhang et al., "Optimization of boltgrouting time for soft rock roadway," Rock and Soil Mechanics, vol. 33, pp. 1395-1401, 2012. 